\title{
From Devaki to Yashoda: The Intra-authorial Mediation in Translating One's Own Plays
}

\section{Ramesh Panigrahi*}

When the translator (the creator of the TL text) and the author (the creator of the SL text) are rolled into a single organism, as in my case, the notion of heirarchization with regard to the creator and translator and Popovic's idea of four equivalences prescribed and searched for during translation are erased. As the nurturing mother (Yashoda) of my own SL text, I am compelled to go about with semantic consideration, circumlocution and transformations that do not alter the core meaning of my own original writing (my creative position metaphorised as Devaki). The TL rendering becomes a rewriting and veritably a new creation in the case of the author translator.

This leads to the dissolution of the idea of the 'correct' and 'invariant' translation which two notions seem to be even otherwise either outdated or irrelevant.

One of the words for "translation" in my source language, Oriya, an Indo-Aryan language, is rupantar. It means 'change of form'. In Oriya, the Mahabharata of Sarala Das (15 th century) is accepted as an original writing even though there are innumerable interpolations of indigenised episodes. This puts paid to Eugene Nida's prescriptions for a 'correct' and 'invariant' version of translation. In a folk version of Ramayana, Sita is treated as Rama's sister in my state and in the Jagannath temple is the only place in India in which a sister is worshipped with her two brothers. Thus, my culture allows all sorts of variation and all variations are accepted as "correct" and adhered to religiously.

I do not translate into English for an improvement in my status. Nor do I translate with a colonial mission to institutionalise English.

Dr. Ramesh Prasad Panigrahi is a reputed playwright in Oriya. After retiring from Govt. service as senior Reader in English at Ravenshaw College, Cuttack, he is now the Designated Board Member, CBFC, Orissa.

Translation Today Volume (1) No (1) Mar 2004 (c) CIIL 2004. 
Translating One's Own Plays

In fact I feel that I am doing justice neither to the SL nor to the literary piece by translating it into a language like English. The aksharas (alphabets) in my language are called varna which also means colour. My native alphabets, like in Sanskrit, have a colour, a gender, are positioned in a chakra and are assigned to a Yogini, whereas the English language has a 'phonetics' that describes only the sounds produced by the lips and the teeth and the tongue etc. It does not undergo a process of transformation from the ParaVak to Baikhari Vak for articulation*. Yet I translate my plays into English and such an effort is perhaps rooted in my inner frustration - the frustration of not being able to share my creative experiences with the Oriya elite reading society. During the forty years of my stage career and with my hundred odd plays I never had any problem with my rural audience. My own plays directed by me for the repertory companies run for 10 to 12 years with 7 to 10 thousand spectators. But I have problems with the so called intellectuals, most of whom are either IAS officer- poets or their sycophant teacher critics who would continuously lobby their way into a project of denouncing the dramatic text as mediocre writing. My intention behind translating play-texts is partly aimed at counteracting such an intellectual prejudice.

Thus, my endeavour in this paper would be to study the process of translation that takes place within this individual authortranslator, a playwright and director in Oriya and a translator into English. These are three distinctly different positions within the inner space. The focus of my paper would be to attempt a hermeneutical approach to translation and my arguments would be advanced purely from my personal experiences. I have been working on the stage for the last four decades as a playwright, for more than two decades as a director, and I have been engaged in practical translation for two decades.

I begin to envision four definite stages of attitudinal transformation in the process of my translation: (a) Trust

*This is the author's opinion, which is clearly untenable. No human language can claim intrinsic superiority on such grounds- Editors 
Comprehension (c) Incorporation and (d) Reciprocity. All these changes within this authorial self are viewed here as mediations between my fragmented selves initiated by a fragment named "Translator". This fragmented author of the TL is codified here as $\mathrm{A}^{2}$ and the writer of the Odia text (SL) is taken as $\mathrm{A}^{1}$. As the director within me is the first functional reader and the interpreter of the text, who has created it for the second time in performing space, he is taken as $\mathrm{A}^{2(\mathrm{a})}$.

\section{(a) Trust:}

The process begins $\mathrm{A}^{2}$ (of the TL) decides translate, which, according to George Steiner's dictionary, is "w carry over from what has been silent to what is vocal, from the distant to the near. But also to carry back" (Steiner). But $\mathrm{A}^{2}$ selects one book in preference to others for this act of "carrying over" and "carrying back". This begins with the assumption that the particular play-text has 'something' which is translatable and the other SL texts are eliminated either because their linguistic, paradigmatic, stylistic or textual equivalences are not available, or because of their inherent cultural untransmissibility.

The criterion of the search initiated by $\mathrm{A}^{2}$ seems too mechanical for $\mathrm{A}^{1}$ who likes all his works to be translated for the extension of his creative self. He does not care for the possible loss in translation as it has been pointed out by Eugene Nida in Towards the Science of Translating. Rather the greedy $\mathrm{A}^{1}$ would quote from Anton Popovic's Dictionary wherein he mentions five kinds of shifts in translation (constitutive, generic, individual, negative and topical shifts) deploying which TL variants could be produced.

As this intra-authorial tension takes place in the process of selection through investment of trust and with multiple readings of the SL, another unacknowledged translator appears to give one more shake to the process of sifting in the linguistic sieve. He is the Director of the SL Text represented here as $\mathrm{A}^{2}$ (a) . As a semiotic translator, he wouldn't search for synonyms and equivalences, but for signs that embed within them a duality in which the 'ungrammatical' would be accepted as mimesis and 'grammatical' within the significance-network of the translation. 
Translating One's Own Plays

$\mathrm{A}^{2 \text { (a) }}$ would, however, search for the linguistic equivalence, but language in his text of translation should have functionality in addition to readability. In India we have dhwani that expresses a threefold sense: abidha (denotative), lakshana (indicative) and vyanjana (suggestive). The translator, while catering to the demands of $\mathrm{A}^{2(\mathrm{a})}$ accepts this semantic value. $\mathrm{A}^{2}$ would, now, after investing one more seesaw screening, would search for four structural features in the text: (a) the acting style deployed in the text (b) the expected role of the audience (c) whether the play falls into the category of realism, fantasy or expressionism, absurd, mixed means theatre or of a hyper- realistic mode mingled with abstract expressionism or some such esoteric brand that the showbiz invents for itself for survival in an era of mega soap operas and (d) the performance space of the play.

A particular acting style would emerge out of a particular syntax and disorders would result in chaotic performance and incommunicative acting style.

\section{(b) Comprehension:}

$\mathrm{A}^{2}$ of my creative space now takes the lead to break the codes by making a critical incursion into the inspired fable of the SL text. The decipherment at this level is dissective and it leaves the shell of the SL Text smashed and the vital layers stripped. But for $\mathrm{A}^{2}$ (the initiator of comprehension), the act is a symbolic rendering of the spiritual dynamics of translation. However, it goes against the naïve inspiration of $\mathrm{A}^{1}$ during the act of comprehension leading to interpretation / translation. It is a primal hunt for meaning.

The interference of $\mathrm{A}^{2}$ (a) at the level of comprehension/ interpretation is more vital. $A^{2}$ (a) would interpret a piece of background music, the movements of the artists from one acting zone to the other, various colours and levels of intensities of light and the stage-designer's positioning of the properties/objectives. Mr. $\mathrm{A}^{2 \text { (a) }}$ demands a nonverbal code to be revealed in which the act of decipherment and decodification is not only "aggressive and dissective, it is also (in Steiner's dramatisation) a bone- shatteringly arduous work". 
The translation of a dramatic text becomes problematic because of its two strands of narrative lines - linguistic and semiotic. $\mathrm{A}^{2}$, always used to the linguistic mode, would deploy his isolating device of langue and parole to relocate (may be to dislocate as well) the semiotic codes or the system's signs to establish the set of combinatory rules that give rise to all its internal relations. Although this turning of the focus toward the structure comes within the limits of linguistic structure, it becomes an extralinguistic reality in relation to the comprehension or interpretation of $\mathrm{A}^{2 \text { (a) }}$.

As a supporter of the semiotic narrative, the Director $\left(A^{2}\right.$ (a) feels the necessity of dechronologizing and relogicizing the dramatic narrative. He may also try to do so by subordinating every syntagmatic (and therefore temporal) aspect of the narrative to a corresponding paradigmatic (and therefore achronological) aspect. The act of $\mathrm{A}^{2}$ (a) is just an extension of linguistics to narrative semiotics, but it also brings about a lot of strategic change of levels in narratology.

\section{(c) Incorporation:}

With all such investments of trust and multiple levels of comprehension, $\mathrm{A}^{2}$ encounters the third stage of his project, in which, he would, now, deal with an attitudinal crisis called "incorporation" - "the import of meaning and of form, the embodiment" (which) "is not made in or into a vacuum. The entire semantic field is crowd". Each of the intra-authorial segments comes forward, ready with its own structures of understanding, to absorb and domestic this esoteric and creative reality, this may dislocate or relocate the whole structure of Devaki's (SL) as it is being nurtured by Yashoda's principles.

I would prefer to cite an example from the translation of my own play, "Drawing a Full Circle", (1985) published in Indian Literature, (1999 Sept - Oct. 2000). The selection of the play for translation is radical in two ways - it alters and modifies a popular myth of Orissa and secondly it showcases a Hindu God as a character on the stage. The character of the God is presented as a politically manoeuvred mask that is idolised as a religious icon and 
the essence behind this religious image (the inner structure of the character) is theatricalised simultaneously through two semiotic signs - musically as a long roll of flute as if heard through the last six thousand years, and sculpturally as a configuration made up by two half circles that constitute a Poorna.

Thus, the translator, or $\mathrm{A}^{2}$, in this case, endeavours to incorporate the entire "cultural ensemble" and a traditional symbolic set into the fabric of an alien linguistic culture. $A^{2}$ cannot. import it without the risk of transforming the SL of his counterpart, $A^{1}$. But a critic, following Bogatyrev's prescription for the translation of play-texts, cannot produce a version that is too "free" and "deviant". He is run through semiotics and with an emphasis on extralinguistic criteria.

Scene 10 of the play may be cited as an example. Stones from the temple of Jagannath are falling down and the temple is on the verge of a collapse. Jagannath is unable to do anything substantial. So, Jogamaya, the temple's American caretaker has asked the tribal girl Jui to adopt some indigenous 'tantric method' to "renovate the temple". Jui is supposed to work out the pooja of a "flower-tantra" which is nowhere prescribed and which is purely a figment of $\mathrm{A}^{1 \text {, }} \mathrm{s}$ imagination, worked out to give a touch of 'magical realism' to the play. A ${ }^{1}$ uses tantric folk music and Jui with her "one-two-three" (three-beat) tribal rhythm decorates the stage with flowerpots. As she decorates, she mutters:

"Flowers of ten colours. And ten shafts of grass. Three pieces of strings to be tied up thrice and a flame has to be burnt with pure ghee... some pure refined rice to be coloured with chalk powder of five colours.... Ten painted pots filled with water and a raw coconut each upon them have to be placed. And mango leaves.... A cock has to be brought and fed with the turmeric rice... then it will be sacrificed."

(a long-drawn inarticulate sound hullhool is heard from a group of women from the background as they do in the Hindu marriage rituals). 
$\mathrm{A}^{2}$ of this translation confesses here that despite a good deal of incorporation, the exact rhythm and language and the performing style could not be transported. $\mathrm{A}^{1}$ of the SL reports that there is no such tantra called flower tantra. The tantric rituals narrated never exist. This is an imitation-ritual created for an ethnic kind of effect and it could not be recreated.

The language used in the SL is an imitation of $10^{\text {th }}-12^{\text {th }}$ century ritualistic Oriya prose and that particular style of prose is recited during a ritual-vow. This typical prose singing is used even today in Berhampur area by the so-called 'untouchable' women during a ritual performance called Oshakothi performed during Dussera, the ten-day festival in October.

Sometimes, a lady Shaman would emerge from nowhere at Bhubaneswar and lots of frustrated and diseased men and women would visit her. She would solve their problems by singing such an impromptu prose song.

Jui's muttering of these ritualistic words do not have any literary meaning since she is bringing the flowers, shafts of grass, flames, rice, coloured with turmeric powder and mango leaves on to the stage. The tantric folk music is played in the background and thus Jui's muttering of the libretto in an incantatory style is just a gateway to the succeeding change of consciousness- the religious trance. Immediately after Jui's incantation there is a jerk in the hulhooli choral and then Jogamaya comes dancing like a Shaman playing to the Oshakothi tantric rhythm which was also the base for Jui's incantation. Jogamaya holds a broom made of peacock feathers and the so-called Lord Jagannath enacts the role of a sacrificial cock.

$\mathrm{A}^{2}$ (a) within me is not, somehow, satisfied with the English rendering. The ordinary words of Jui could automatically become nonordinary because of the $10^{\text {th }}-12^{\text {th }}$ century lexical and syntactic forms in the SL and its English rendering could not be made as archaic as in the SL carrying over the original semantic content. Jui's accent and intonation pattern could not be incorporated in the TL. 
There has also been an exact failure with regard to its semiotic transportation of the scene does not exactly drive religious belief, the trance could successfully be induced by the tantric folk rhythm of Oshakothi and the scenic transformation achieved through the arrangement of the flower pots and the rhythmic movements of Jui, Yogamaya and Jagannath along with Jui's archaic incantations. I do. . not know personally what would happen if Indian experts of the post-colonial era think of an Indo-Anglian production of this play. The same thing happened to Sam Shepard's plays when he introduced the Hopi dance and rituals in his play, Operation Sidewinder. The musical notations were printed on the text, but it further obfuscated the play's musical import.

\section{(d) Reciprocity}

The fourth and the final stage of experience that comes to the translator is the enactment of reciprocity. Whether the translator does his act successfully or not, he takes a great deal from the SL and as Steiner points out, "we come home laden" and this causes "disequilibria through out the system by taking away from "the other' and by adding... to our own.... The hermeneutic act must compensate... it must mediate into exchange... it enlarges the stature of the original".

So, at the final stage, the mediation of $\mathrm{A}^{2}$ ends up as a creative exchange or as a negotiation for a creative exchange between the SL and the TL. It is a hermeneutic decision towards compensating for what has been taken away in the process of translation.

As the $T^{2}$ proceeds now to exchange in reciprocity, he feels obliged to alter the contours and the structures of the TL as it was done in this author's translation of Jui's archaic incantation in Drawing a Full Circle. If it is not a successful transportation, the translator, at least, brings a bearable perspective when he encounters the impasse of "untranslatability" in the culturallinguistic matrix. In this process of reciprocity (exchangeability) between the SL and the TL, these alterations and substitutions can be called the process of "alternity".

Alternity positions the art, craft and science of translation studies in the realm of hermeneutics. Hermeneutics branches off 
into two directions: (a) the theory and practice of understanding and (b) value judgement / aesthetics. If there is anything called a theory of understanding, it is nothing as a presence through interpretation. Although the tribal-archaic rhythm and intonation are absent in the English rendering of Jui's mutterings during the flower-tantra, the shadow of the effect remains.

But "alternity" cannot be given to $\mathrm{A}^{2}$ as a license for infinite exchangeability so that he would lapse into an uncharted jungle of creations where the enormity of being delinks from the subatomic unit of structure. This demands multiple readings as a pre-requisite for reciprocity in translation. The multiple layers of writings that constitute a text and generate contestations, parody and dialoguing amongst them get united at a site called the 'reader', enacted here by $\mathrm{A}^{2}$.

Interestingly enough, the author of the SL text $\left(\mathrm{A}^{1}\right)$ has already vacated his position and disappeared within this writer's inner space, and the new author $\left(\mathrm{A}^{2()} /\right.$ translator $)$ has not yet appeared on the scene when this reader begins to understand the SL as a prerequisite. One fragment of my split-self known as $\mathrm{A}^{1}$ backs off and leaves the space for the other fragment, $\mathrm{A}^{2}$ who mediates now as a reader or a pre-translator (Let us symbolise this authorial fragment as $\mathrm{A}^{-2}$ ). $\mathrm{A}^{-2}$, as a reader, assumes at least five different roles as he mediates with $A^{1}$ : as a mock reader $\left(A^{-2}(a)\right)$, as a model reader $\left(A^{-2(b)}\right)$, as an implied reader $\left(A^{-2(c)}\right)$, as a super reader $\left(A^{-2}\right.$ (a) or as the real reader $\left(\mathrm{A}^{-2}\right.$ (e) $)$. The understanding of the SL with its multiple layers of converting himself into a Translator, this authorial fragment within this author joins the interpretative community. This requires a literary competence in $\mathrm{A}^{-2}$ who would soon emerge as $\mathrm{A}^{2}$. The "multiple writings" playing through and pulverizing the once closed, organic, stable, objective, autonomous text can hardly remain absent from $\mathrm{A}^{-2}$. However, $\mathrm{A}^{1}$ and $\mathrm{A}^{2}$ would not allow $\mathrm{A}^{-2}$ to imprint his private fantasies, desires and neurosis in a radically in a personal way upon the SL.

As I intend to define actual position of $\mathrm{A}^{-2}$, I discover a mixed bag of critical writings, sharing an orientation towards the role of the reader who is given an important chair in pedagogical enterprises to decide on the locus and nature of literary meaning. 
Stanley Fish would define Reading as Meaning and vice-versa, but 'meaning' is not a content, but an event. He would then go into the details to analyse the dynamics of the event.

This reader's $\left(\mathrm{A}^{-2} \mathrm{~s}\right)$ position is toppled when he assumes the role of the translator. $\mathrm{Mr} . \mathrm{A}^{2}$ (a) , the director, would emerge from my authorial space and warn $\mathrm{A}^{-2}$ that he is only a reader, not a spectator. This is to remind the $\mathrm{A}^{2}$ that play-texts do have two "addresses" and the performances are addressed to spectators through the performers. In other words, the director claims himself to be the first translator of the play-text. The performing group undertakes the second phase of translation and the reception of the play involves a "relay"-like process: first received by the performers and then by the spectators, who are also translators.

The spectators are substitute readers, but "reading" in their case is an aesthetic experience and a pure event. The interpretative procedures applied for other translators of other genres would be wholly different from the translator of play-texts. There is one convenience for $\mathrm{A}^{2}$ that the plurality of the theatrical metalanguages (in the SL) can pass on more safety to the TL than the translation of the literature. However, the translator would never be in a position to know whether the play emotes the spectator through Aristotelian "catharsis" or de-emotes them through Brechtian "alienation".

With all these intra-authorial mediations the $\mathrm{T}^{2}$ in me travels through two stages: the first stage on which I go from source to "literal" translation and, then, a second stage of post writing, in which the product is given a finishing touch. During the second stage of postwriting, the translator is distantiated from the tooliteral, too-influential, original and the revision is expected to produce a more "natural" version. The first phase translation is done without any literary ambitions, but with an expertise in the foreign language and a striving to be "literal". The $\mathrm{T}^{2}$ relates his source to one more remove from himself and it is a shift of stance: from a "source-oriented" to a "reader-oriented" practice of translation. I do not know what the translators of poems do, but in translating drama, the second phase is required for performative characterisation. It is a kind of cosmetic surgery and during this phase, editing is done with little or no consultation with either the 
source $\left(A^{1}\right)$ or the translator $\left(A^{2}\right)$ who in this intra-authorial scheme are ignored.

Seekers of fidelity in translation would, perhaps, notice a flouting of the norms here, but since the act of translation requires an axiomatic leap toward meaning-"fullness", there can be no striving toward intelligibility or value-judgement, however provisional it might be, without such a revision. This is an enactment it might be, without such a revision. This is an enactment of 'reciprocity', or a mediation into "exchai "." However, with these revisions, the $\mathrm{T}^{2}$ within me proceeds : in to recross the divide of language and community only to bri ut a simulacrum of the original. But this act of interpretation represent movements across borders; and perhaps, includes some transaction oetween the secular (with the freedom to deviate) and the transcendent (which might also result in the production of the simulacrum). The $\mathrm{T}^{2}$ within me does not take it as a flirtation with the mystical or the irrational. Thus, this author-translator is habituated not only to a startling combination of learning and humility, but also to a sense of high purpose. Perhaps, this is a paradox embedded in the experience of a translator.

As a concluding remark I would like to confess that the sound of a flute or the visual of a sculpture transports the value of my play more successfully than words.

\section{References}

Das, Bijay K. 1998 The Horizon of Translation Studies. New Delhi: Atlantic Publishers and Distributors.

McGuire Bassnet, Susan 1980 Translation Studies. London, New York: Methuen and Co.

Nida, Eugene 1964 Towards The Science of Translating - With Special Reference to Principles and Procedures involved in Bible Translating. Leidon: E.J.Brill.

Popovic, Anton 1976 Dictionary for the Analysis of Literary Translation. Deptt. Of Comparative Literature. Univ. of Alberta. 
From Devaki to Yashoda: The Intra-authorial Mediation in

Translating One's Own Plays

Sharp, Ronald A. 1989 Interrogation at the Borders: George Steiner and the trope of translation in New Literary History. Vol.21. No.1. pp.133-161.

Steiner, George 1966 "Introduction" to his The Penguin Book of Modern Verse Translation. Harmondsworth.

Swanson, J.W. 1961 Linguistic Relativity and Translation in Philosophy and Phenomenological Research.

-Vol.XXII. No.2. Dec 1961. Philadelphia PA. pp. 185-192. 